\title{
The Effect of Medication-related Support on the Quality of Life of Patients with Vasculitis in Relapse and Remission
}

\author{
DELESHA M. CARPENTER, PhD, MSPH [Postdoctoral Fellow], \\ UNC Thurston Arthritis Research Center, University of North Carolina (UNC) Thurston Arthritis \\ Research Center, Chapel Hill, North Carolina, USA
}

JESSICA A. KADIS, MPH [Doctoral Student], University of North Carolina (UNC) Thurston Arthritis Research Center, Chapel Hill, North Carolina, USA

ROBERT F. DEVELLIS, PhD [Research Professor], UNC Department of Health Behavior and Health Education, University of North Carolina (UNC) Thurston Arthritis Research Center, Chapel Hill, North Carolina, USA

SUSAN L. HOGAN, PhD [Research Associate Professor], and UNC Kidney Center, University of North Carolina (UNC) Thurston Arthritis Research Center, Chapel Hill, North Carolina, USA

JOANNE M. JORDAN, MD [Director]

UNC Thurston Arthritis Research Center, University of North Carolina (UNC) Thurston Arthritis Research Center, Chapel Hill, North Carolina, USA

\section{Abstract}

Objective-Few studies have investigated whether the utility of social support for patients with a relapsing, remitting illness varies by activity level of the disease. Our goal was to determine whether disease status (relapse vs remission) moderates the effect of medication-related support from physicians and partners on the health-related quality of life (HRQOL) of patients with vasculitis.

\begin{abstract}
Methods-Patients with vasculitis $(n=228)$ completed baseline measures of disease status and medication-related support and a 3-month followup measure of HRQOL (RAND 36-item health survey 1.0). We calculated 8 HRQOL dimensions: physical functioning, physical role limitations, bodily pain, general health, vitality, social functioning, emotional role limitations, and mental health. Bonferroni-corrected $t$ tests compared the HRQOL of patients in relapse to patients in remission, and multivariate analysis of covariance determined whether disease status moderated the effect of medication-related support from physicians and partners on patient HRQOL. Wilks' lambda assessed whether the support-by-disease status interaction terms were significant.
\end{abstract}

\begin{abstract}
Results-Relapsing patients reported significantly worse quality of life compared with nonrelapsing patients for every HRQOL dimension except physical role limitations. Disease status did not moderate the effect of physician (lambda $=0.48 ; \mathrm{p}=0.86$ ) or partner (lambda $=1.51 ; \mathrm{p}=$ 0.16 ) medication-related support on HRQOL, although greater physician and partner support predicted better HRQOL for all dimensions except bodily pain and vitality.
\end{abstract}

The Journal of Rheumatology Copyright (C) 2011. All rights reserved.

Address correspondence to D. Carpenter, Thurston Arthritis Research Center, 3300 Thurston Bowles Building, CB7280, Chapel Hill, NC 27599. dmcarpenter@unc.edu. 
Conclusion-Vasculitis patients experience compromised HRQOL but the magnitude of the compromise is greater for patients experiencing a relapse. Medication-related support from physicians and partners is beneficial for patients' HRQOL regardless of disease status.

\section{Keywords}

VASCULITIS; QUALITY OF LIFE; SOCIAL SUPPORT

Over the past 40 years, the advent of more effective drug regimens has transformed vasculitis from a frequently fatal, acute disease to a chronic condition with relapsing and remitting episodes. Despite treatment with remission maintenance regimens, $30 \%$ to $60 \%$ of vasculitis patients will experience a relapse, potentially causing organ damage, hospitalization, or death ${ }^{1,2,3}$.

Similar to other chronic diseases, vasculitis has negative effects on patients' physical and mental health, including decreased physical functioning and increased depression $4,5,6,7,8,9,10,11,12,13$. Beyond reductions in health-related quality of life (HRQOL), patients often experience other negative sequelae. For example, the unpredictable course of relapse and remission can cause patients to miss up to 6 consecutive weeks of work, leading to financial $\operatorname{strain}^{5,7,14}$.

Although research has shown that vasculitis patients in remission report worse HRQOL than healthy controls ${ }^{4}$, little is known about whether relapses further compromise patients'

HRQOL. Moreover, we are unaware of any published studies that have investigated whether medication-related support affects the HRQOL of vasculitis patients in relapse and remission differently. Studies of other chronic diseases consistently demonstrate that more social support is associated with better physical and mental health outcomes ${ }^{15,16}$, and that partners $^{16,17,18,19,20}$ and physicians ${ }^{21,22,23,24}$ are important sources of emotional and informational support for patients.

Using longitudinal data, we attempted to address the research gaps described above by comparing 8 domains of HRQOL for vasculitis patients in relapse and remission. We also examined whether disease status, defined as relapse versus remission, moderated the effect of medication-related social support from physicians and partners on patients' HRQOL.

\section{MATERIALS AND METHODS}

All data were collected as part of the Accessing Social Support in Symptom Treatment (ASSIST) Study, which evaluated the level of support of vasculitis patients' social networks, especially with regard to medication management. The ASSIST Study consisted of 2 online questionnaires administered 3 months apart. Eligible patients had a self-reported diagnosis of vasculitis, were at least 18 years of age, were able to read and write in English, had Internet access, and were taking at least one medication to treat their vasculitis. This study was approved by the Institutional Review Board at the University of North Carolina at Chapel Hill.

\section{Sample}

We recruited 106 participants for the ASSIST Study by distributing study information to attendees at a vasculitis patient conference $(\mathrm{n}=39)$ and mailing to physician-diagnosed vasculitis patients who were part of the Glomerular Disease Collaborative Network $(\mathrm{n}=38)$ and previous vasculitis studies $(\mathrm{n}=29)$. We also contacted members of vasculitis support groups and posted announcements on vasculitis websites, in patient newsletters, and on 
patient list-serves, which yielded 147 eligible and interested participants. Carpenter and colleagues provide a thorough description of recruitment procedures ${ }^{25}$.

Of the 253 eligible patients, 232 (91.7\%) completed the 1-hour baseline questionnaire. Reasons for noncompletion included never responding to study correspondence $(n=7)$, technical issues $(n=7)$, or being too sick $(n=4)$ or too busy $(n=3)$ to participate.

Compared with completers, non-completers were not significantly different in terms of gender or self-reported vasculitis type.

Only 4 of the 232 participants were lost to followup for the second questionnaire, resulting in a response rate of $98.2 \%$. Participants who completed both questionnaires received a $\$ 10$ gift card.

\section{Measures}

The baseline survey contained measures of physician support, partner support, disease status, and sociodemographic variables. The 3-month followup questionnaire contained the HRQOL measure.

\section{Physician and partner medication-related support}

Participants completed 4 items about perceived medication-related adherence support from their primary vasculitis physician $(\alpha=0.80)$ and their partner $(a=0.79)$. Specifically, participants indicated how often their physician or partner supported them in taking their vasculitis medications, shared new information about vasculitis medicines, provided helpful hints about how to deal with the medication side effects, and provided enough support for taking their medications as prescribed. Response options ranged from $1=$ "does not do this" to $4=$ "does this a lot." Responses of "not applicable" were recoded as " 1 " to indicate that the physician or partner did not provide that type of support. We created a summary score by averaging the 4 items; higher scores (range of 1-4) reflected more support.

\section{Disease status}

Participants reported their disease status as "currently experiencing a flare/relapse" or "not currently experiencing a flare/relapse."

\section{Sociodemographics}

Participants answered one item each about gender, race (white vs non-white), age, education (in years), year of vasculitis diagnosis, health insurance status (insured vs not insured), and vasculitis type [antineutrophil cytoplasmic autoantibody (ANCA)-associated granulomatous vasculitis vs other].

\section{Health-related quality of life}

We used the RAND 36-item health survey v 1.0 to assess HRQOL ${ }^{26}$. The measure assesses 8 domains of HRQOL, including physical functioning ( 10 items, $a=0.93$ ), bodily pain ( 2 items, $a=0.91$ ), role limitations due to physical health (4 items, $a=0.88$ ), role limitations due to emotional health ( 3 items, $a=0.87$ ), mental health ( 5 items, $a=0.85$ ), social functioning ( 2 items, $a=0.90$ ), vitality ( 4 items, $a=0.91$ ), and general health perceptions ( 5 items, $a=0.82$ ). For all subscales, higher scores correspond to better HRQOL.

For the multiple-item scales described above, summary scores were treated as missing if more than $25 \%$ of the scale items were missing. 


\section{Data analysis}

All analyses were conducted using SAS v 9.2. We converted the HRQOL subscale scores to norm-based scores using procedures described by Ware and Kosinski ${ }^{27}$. Norm-based HRQOL scores indicate how the population of interest scored with respect to the general 1998 US population (score $=50$ ). For this study, we provided age-adjusted HRQOL comparisons by comparing norm-based HRQOL scores for patients in relapse and remission to norm-based scores for the general US population aged 54-65 years (i.e., age group corresponding to the mean age of our patient sample). Bonferroni-corrected independent sample $t$ tests $(a=0.05 / 8$ or 0.00625$)$ were used to determine whether patients experiencing a relapse differed from patients in remission for each of the 8 domains.

To investigate whether disease status moderated the effect of physician and partner support on HRQOL, we created 2 interaction terms: disease status-by-physician support and disease status-by-partner support. We then ran 2 separate multivariate analysis of covariance (MANCOVA) models looking at the effects of physician support and partner support on patient HRQOL. We chose to investigate the effects of physician and partner support independently because they were moderately correlated $(r=0.41)$. In both MANCOVA models, the dependent variables were the 8 patient HRQOL subscales, independent variables were physician or partner support and disease status, the moderating variable was the disease status-by-support interaction term, and the control variables were patient gender, age, race, education, years since diagnosis, vasculitis type, and health insurance status. For each MANCOVA model, we inspected Wilks' lambda for the interaction term as well as disease status and support. If the Wilks' lambda values were significant, we inspected individual univariate analysis of covariance (ANCOVA) models to determine where differences existed. To further describe the effects of medication-related support on each HRQOL domain, we estimated the slopes for the effect of support on HRQOL for patients in relapse and remission.

\section{RESULTS}

\section{Sample characteristics}

The majority of participants $(\mathrm{n}=228$, Table 1$)$ were female, white, and had a diagnosis of ANCA-associated granulomatous vasculitis. On average, participants were middle-aged, had completed some college education, and had been living with vasculitis for 6.4 years. Twenty-eight percent were experiencing a relapse or flare at the time of the baseline survey. Patients in both relapse and remission reported moderate amounts of support from their physicians $($ mean $=2.1)$ and partners $($ mean $=2.1)$. Patients in remission reported more education than relapsing patients (chi-square $2=7.31, \mathrm{p}=0.03$ ) and were more likely to have a diagnosis of ANCA-associated granulomatous vasculitis (chi-square $4=12.60, \mathrm{p}=0.01$ ).

\section{HRQOL of patients in relapse and remission}

Figure 1 presents the norm-based HRQOL scores for vasculitis patients experiencing a relapse, patients in remission, and the 1998 general US population aged 55-64 years. Relapsing patients scored significantly worse than patients in remission on all HRQOL subscales, with the exception of physical role limitations (Table 2).

\section{Effect of physician medication-related support and disease status on HRQOL}

The Wilks' lambda for the disease status-by-physician support interaction term was insignificant (lambda $=0.48 ; \mathrm{p}=0.87$ ), indicating that physician support did not differentially affect HRQOL for those experiencing a relapse compared to those in remission. In a main-effects model without the interaction term, relapsing disease status $($ lambda $=2.76 ; \mathrm{p}<0.01)$ and less physician support (lambda $=2.21 ; \mathrm{p}=0.03)$ were 
statistically significant predictors of lower HRQOL. The 8 ANCOVA models (Table 3) revealed that relapsing disease status was a significant predictor of worse health for every HRQOL dimension except physical role limitations. Higher physician support was a significant predictor of better health for all HRQOL dimensions except bodily pain and energy. One control variable, gender, also strongly influenced HRQOL; female patients reported lower HRQOL than male patients for 6 of 8 dimensions.

To investigate the nature of the physician support-by-disease status interaction term, we estimated the slope for the effect of physician support on each HRQOL dimension for those in relapse and remission. As Table 4 shows, the slope for physician support was greater for relapsing patients for every dimension of HRQOL except social functioning. The $95 \%$ confidence intervals were significant for 4 of 8 HRQOL dimensions for relapsing patients, but for only one of 8 dimensions for patients in remission. Regarding interpretation, the slope for the effect of physician support on physical functioning was 4.23 for patients in relapse and 1.95 for patients in remission. This means that for every 1-point increase in physician support, patients experiencing a relapse reported a 4.23-point increase in physical functioning, whereas patients in remission reported only a 1.95-point increase in physical functioning.

\section{Effect of partner medication-related support and disease status on HRQOL}

In the MANCOVA model that explored whether disease status moderated the effect of partner support on patient HRQOL, the disease status-by-partner support interaction term was not significant (lambda $=1.51 ; \mathrm{p}=0.16$ ). In the model without the interaction term, relapsing disease status (lambda $=2.06 ; \mathrm{p}=0.04$ ) and less partner support (lambda $=2.35 ; \mathrm{p}$ $=0.02$ ) were both statistically significant predictors of lower HRQOL. Individual ANCOVA models revealed that relapsing disease status was significantly associated with 4 of 8 HRQOL dimensions, including more bodily pain, worse general health, worse social functioning, and worse mental health. More partner support was significantly associated with better HRQOL for 6 of 8 dimensions (Table 5); support was not associated with bodily pain or vitality.

Again, we estimated the slopes for the effect of partner support on each HRQOL dimension for those in relapse and remission (Table 4). The slope for partner support was greater for relapsing patients for every dimension of HRQOL, meaning that the benefit to HRQOL due to increasing partner support was consistently greater for relapsing patients than patients in remission. The $95 \%$ confidence intervals were significant for 5 of 8 HRQOL dimensions for relapsing patients and 3 of 8 dimensions for patients in remission. The largest slope difference was for emotional role limitations: for every 1-point increase in partner support, relapsing patients experienced a 10.86-point improvement in emotional role limitations, whereas patients in remission experienced only a 3.46-point improvement.

\section{DISCUSSION}

Similar to previous studies $4,5,6,7,8,9,10,11,12$, our results indicate that vasculitis has negative effects on patients' physical and mental quality of life. Vasculitis patients scored lower than the general US population (ages 55-64 yrs) on every HRQOL dimension. Further, compared to patients in remission, relapsing patients reported significantly worse quality of life on all physical and mental health dimensions except physical role limitations, which trended toward significance. Relapses exacted a physical and mental toll on patients' HRQOL over and above what was experienced during remission.

Our results are similar to those of Linde and colleagues ${ }^{28}$, who found that patients with rheumatoid arthritis with higher physician-rated disease activity reported statistically 
significant reductions in HRQOL compared to patients in remission and to the general US

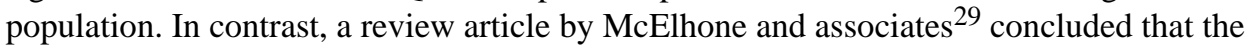
correlation between physician-rated disease activity and HRQOL was weak or nonexistent for patients with systemic lupus erythematosus. Similarly, Koutantji and colleagues ${ }^{8}$ found no association between disease activity and HRQOL for patients with primary systemic vasculitis. Thus, findings regarding the effect of disease activity on HRQOL remain mixed.

Support from physicians and partners was associated with better physical and mental health, as found with previous studies ${ }^{15,16,17,18,19,20,21,22,23,24}$. However, support was not associated with bodily pain or vitality. One might expect that medication-related support would have a greater influence on pain and vitality because improved adherence to medication might be related to a decrease in symptoms. It appears that support from physicians and partners in this study had a weaker effect on physical symptoms than on a general sense of well-being that arose from perceiving others as caring. Thus, medicationrelated support may have yielded stronger associations with more general outcomes, such as physical and social functioning, than on more specific physical symptoms. The data from this study, however, cannot confirm that interpretation.

We did not find evidence that relapsing disease status moderated the effect of social support on HRQOL, but it is difficult to put these results into a broader context because there has been little work in this area. One study by Bae and colleagues ${ }^{30}$ found that social support was more beneficial for lupus patients' physical functioning during periods of lower disease activity in contrast to greater disease activity. The discrepancy between our results and those of Bae, et al may be due to the use of a patient-reported, rather than a physician-reported, measure of disease activity. Because patients have access to information about their own illness experiences that may be difficult for physicians or other observers to incorporate into their disease activity ratings, observing patients' personal experiences about how their illness affects them seems necessary to predict HRQOL. Ideally, future research will incorporate both patient and physician-reported disease activity measures to determine whether each measure offers unique information in the prediction of HRQOL.

Although the pattern of slopes for physician and partner support were consistent with moderation, the disease status-by-support interaction terms in the multivariate models were not significant. One possible explanation is that relapsing disease status was so strongly associated with HRQOL that it did not leave much additional variation for the interaction term to explain. If we had more relapsing patients in our sample, we may have been able to detect a significant interaction term. Future studies should attempt to recruit a larger sample of relapsing patients and compare them to patients in remission and healthy controls to determine whether the trends seen in our results are replicable and statistically significant.

Our results suggest that gender may act as a moderator of the relationship between support and HRQOL, although we did not formally test this interaction due to small cell sizes that resulted from further dividing the sample. As documented by Revenson and colleagues ${ }^{31}$, there are substantial differences in how men and women cope with chronic illness. Thus, research exploring whether women benefit more from support during a relapse than men is warranted.

Generalizability is limited by our sample's lack of diversity, which was predominantly older, female, and white. Because the study surveys were completed online, our sample may have been more motivated, better educated, and had greater resources than the general vasculitis population, possibly contributing to the lack of a significant interaction between support and disease status. Additionally, self-reported diagnoses of vasculitis may not be completely accurate. For our analyses, we grouped multiple types of vasculitis patients 
together (e.g., Takayasu's arteritis, Churg-Strauss syndrome, microscopic polyangiitis) in order to compare them to ANCA-associated granulomatous vasculitis. It is possible that this grouping masked differences in quality of life attributable to permanent disease damage, which can differ for different types of vasculitis ${ }^{32}$. Further, our ability to assert a causal relationship between support and HRQOL is limited because we were unable to control for baseline HRQOL. Finally, because we combined "not applicable" responses with "does not do this" responses for our social support measures, we cannot differentiate between people who thought support was unimportant/unnecessary from those who thought support mattered but were not receiving it. More sophisticated measures of support that include a response category such as "I do not need this type of support" could be used in the future to make distinctions between those who want but are not receiving support and those who do not want support.

Our findings indicate that vasculitis negatively affects patients across multiple quality of life domains and that relapses further compromise patients' physical and mental functioning. Social support from physicians and partners helped reduce the negative impact of vasculitis on HRQOL regardless of where patients were in the cycle of relapse and remission. Because social support was not associated with improvements in pain or vitality, addressing treatment options for physical symptoms during office visits may benefit patients more than simply offering medication-related support. Even though physicians have less frequent contact with patients than partners, physician support positively affected patients' physical and mental quality of life. Thus, conveying support to the patient during office visits may exert a lasting, positive effect. Replication of our results with larger samples and more general support measures is necessary before concluding that social support is equally beneficial for patients during relapse and remission.

\section{Acknowledgments}

We thank the Vasculitis Foundation, its support group leaders, Vasculitis Foundation Canada, Wegener's Granulomatosis Support Group Of Australia Inc., the Glomerular Disease Collaborative Network, the UNC Kidney Center (especially Ronald J. Falk, Kristen Hendrickson, and Caroline E. Jennette), and Jim Bornac for their help with recruitment. We also thank Chris Wiesen at the Odum Institute for statistical assistance.

Supported by the Thurston Arthritis Research Center Postdoctoral Fellowship (5T32-AR007416), the Renal Epidemiology Predoctoral Traineeship at the UNC Kidney Center, and the ACR REF/Abbott Health Professional Graduate Student Research Preceptorship.

\section{REFERENCES}

1. Walsh M, Jayne D. Rituximab in the treatment of anti-neutrophil cytoplasm antibody associated vasculitis and systemic lupus erythematosus: past, present and future. Kidney Int. 2007; 72:676-82. [PubMed: 17609693]

2. Hogan SL, Falk RJ, Chin H, Cai J, Jennette CE, Jennette JC, et al. Predictors of relapse and treatment resistance in antineutrophil cytoplasmic antibody-associated small-vessel vasculitis. Ann Intern Med. 2005; 143:621-31. [PubMed: 16263884]

3. Mukhtyar C, Luqmani R. Disease-specific quality indicators, guidelines, and outcome measures in vasculitis. Clin Exp Rheumatol. 2007; 25(Suppl 47):120-9. [PubMed: 18021517]

4. Herlyn K, Reinhold-Keller E, Zeidler A, Raspe H, Gutfleisch J, Peter HH, et al. Health-related quality of life in primary systemic vasculitides [abstract]. Arthritis Rheum. 1998; 41:S538. Suppl.

5. Hoffman GS, Drucker Y, Cotch MF, Locker GA, Easley K, Kwoh K. Wegener's granulomatosis: Patient-reported effects of disease on health, function, and income. Arthritis Rheum. 1998; 41:2257-62. [PubMed: 9870883]

6. Reinhold-Keller E, Herlyn K, Wagner-Bastmeyer R, Gutfleisch J, Peter HH, Gross WL. Effect of Wegener's granulomatosis on work disability, need for medical care, and quality of life in patients younger than 40 years at diagnosis. Arthritis Rheum. 2002; 47:320-5. [PubMed: 12115163] 
7. Boomsma MM, Bijl M, Stegeman CA, Kallenberg CG, Hoffman GS, Tervaert JW. Patients' perceptions of the effects of systemic lupus erythematosus on health, function, income, and interpersonal relationships: a comparison with Wegener's granulomatosis. Arthritis Rheum. 2002; 47:196-201. [PubMed: 11954014]

8. Koutantji M, Harrold E, Lane SE, Pearce S, Watts RA, Scott DG. Investigation of quality of life, mood, pain, disability, and disease status in primary systemic vasculitis. Arthritis Rheum. 2003; 49:826-37. [PubMed: 14673970]

9. Jayne D, Rasmussen N, Andrassy K, Bacon PA, Tervaert JWC, Dadoniene J, et al. A randomized trial of maintenance therapy for vasculitis associated with antineutrophil cytoplasmic autoantibodies. New Engl J Med. 2003; 349:36-44. [PubMed: 12840090]

10. Seo P, Min Y, Holbrook JT, Hoffman GS, Merkel PA, Spiera R, et al. Damage caused by Wegener's granulomatosis and its treatment: Prospective data from the Wegener's Granulomatosis Etanercept Trial. Arthritis Rheum. 2005; 52:2168-78. [PubMed: 15986348]

11. Thorpe, C. Illness self-management among adults living with ANCA small vessel vasculitis [dissertation]. University of North Carolina at Chapel Hill; Chapel Hill: 2006. p. 247

12. Akar S, Can G, Binicier O, Aksu K, Akinci B, Solmaz D, et al. Quality of life in patients with Takayasu's arteritis is impaired and comparable with rheumatoid arthritis and ankylosing spondylitis patients. Clin Rheumatol. 2008; 27:859-65. [PubMed: 18097710]

13. Carpenter DM, Thorpe CT, Lewis MA, DeVellis RF, Hogan SL. Health-related quality of life for patients with vasculitis and their spouses. Arthritis Care Res. 2009; 61:259-65.

14. Cotch MF. The socioeconomic impact of vasculitis. Curr Opinion Rheumatol. 2000; 12:20-3.

15. Revenson TA, Schiaffino KM, Majerovitz SD, Gibofsky A. Social support as a double-edged sword: The relation of positive and problematic support to depression among rheumatoid arthritis patients. Soc Sci Med. 1991; 33:807-13. [PubMed: 1948172]

16. Manne SL, Zautra AJ. Spouse criticism and support: their association with coping and psychological adjustment among women with rheumatoid arthritis. J Personality Soc Psychol. 1989; 56:608-17.

17. Uchino B. Social support and health: A review of physiological processes potentially underlying links to disease outcomes. J Behav Med. 2006; 29:377-87. [PubMed: 16758315]

18. Cutrona, CE. Social support in couples. Sage Publications; Thousand Oaks, CA: 1996.

19. Okun MA, Keith VM. Effects of positive and negative social exchanges with various sources on depressive symptoms in younger and older adults. J Gerontol B Psychol Sci Soc Sci. 1998; 53:420.

20. DiMatteo MR. Social support and patient adherence to medical treatment: a meta-analysis. Health Psychol. 2004; 23:207-18. [PubMed: 15008666]

21. Helgeson VS, Cohen S. Social support and adjustment to cancer: Reconciling descriptive, correlational, and intervention research. Health Psychol. 1996; 15:135-48. [PubMed: 8681922]

22. Yates B. The relationships among social support and short- and long-term recovery outcomes in men with coronary heart disease. Res Nurs Health. 1995; 18:193-203. [PubMed: 7754090]

23. Neuling S, Winefield H. Social support and recovery after surgery for breast cancer: frequency and correlates of supportive behaviours by family, friends, and surgeon. Soc Sci Med. 1988; 27:38592. [PubMed: 3175721]

24. Dunkel-Schetter C. Social support in cancer: findings based on patient interviews and their implications. J Social Issues. 1984; 40:77-98.

25. Carpenter DM, DeVellis RF, Hogan SL, Fisher EB, DeVellis BM, Jordan JM. The effect of conflicting medication information and physician support on medication adherence for chronically ill patients. Patient Educ Couns. 2010; 81:169-76. [PubMed: 20044230]

26. Hays RD, Sherbourne CD, Mazel RM. The RAND 36-item health survey 1.0. Health Econ. 1993; 2:217-27. [PubMed: 8275167]

27. Ware, JE.; Kosinski, M. SF-36 physical and mental health summary scales: A manual for users of Version 1. QualityMetric Inc.; Lincoln, RI: 2005.

28. Linde L, Sorensen J, Ostergaard M, Horslev-Petersen K, Hetland M. Does clinical remission lead to normalization of EQ-5D in patients with rheumatoid arthritis and is selection of remission criteria important? J Rheumatol. 2010; 37:285-90. [PubMed: 20080905] 
29. McElhone K, Abbott J, Teh L-S. A review of health related quality of life in systemic lupus erythematosus. Lupus. 2006; 15:633-43. [PubMed: 17120589]

30. Bae SC, Hashimoto H, Karlson EW, Liang MH, Daltroy LH. Variable effects of social support by race, economic status, and disease activity in systemic lupus erythematosus. J Rheumatol. 2001; 28:1245-51. [PubMed: 11414264]

31. Revenson, TA.; Abraido-Lanza, A.; Majerovitz, SD.; Jordan, C. Couples coping with chronic illness: what's gender got to do with it?. In: Revenson, TA.; Kayser, K.; Bodenmann, G., editors. Couples coping with stress. American Psychological Association; Washington, DC: 2005. p. 137-56.

32. Sable-Fourtassou R, Cohen P, Mahr A, Pagnoux C, Mouthon L, Jayne D, et al. Antineutrophil cytoplasmic antibodies and the Churg-Strauss syndrome. Ann Intern Med. 2005; 143:632-8. [PubMed: 16263885] 


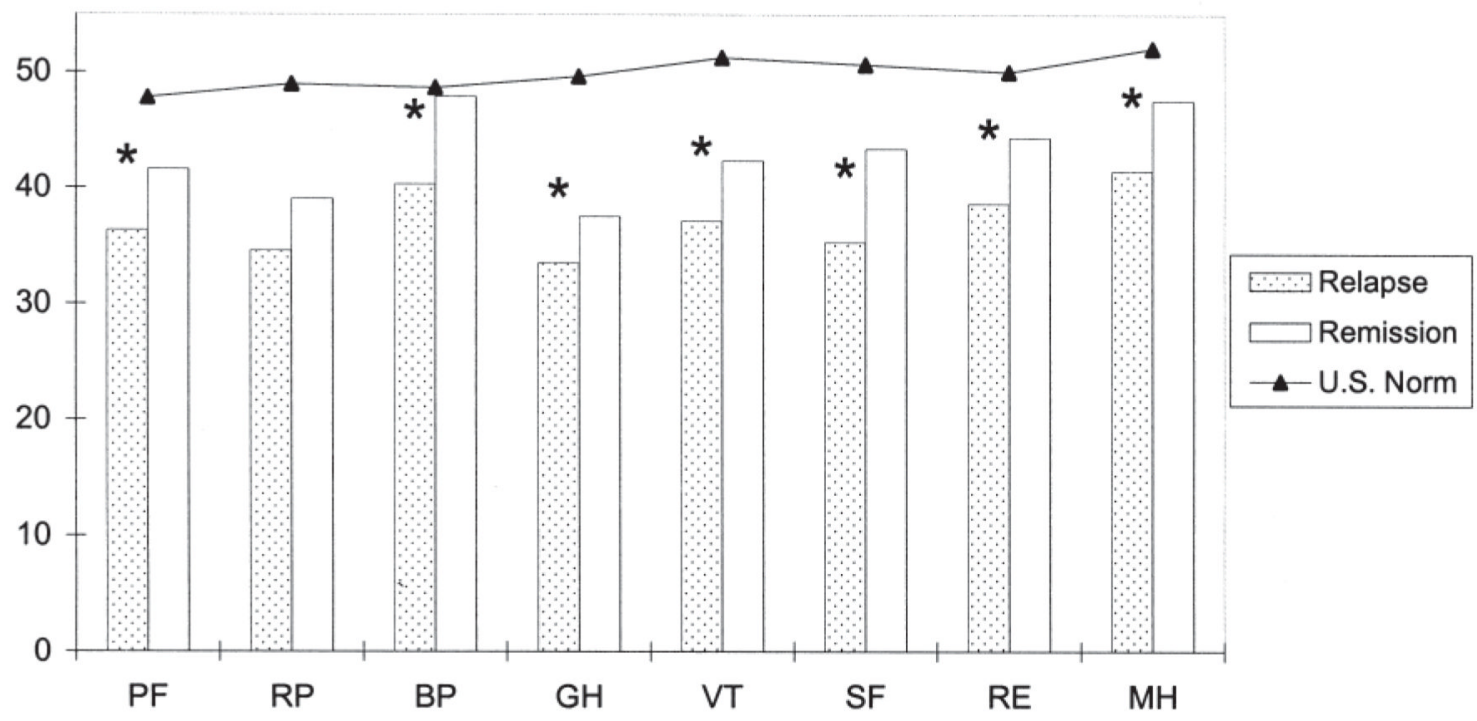

Figure 1.

Norm-based health related quality of life scores for patients with vasculitis in relapse $(\mathrm{n}=$ $64)$ and in remission $(n=164)$ and a 1998 general US population, ages 55-64 years 27 . PF: physical functioning, RP: physical role limitations, BP: bodily pain, GH: general health, VT: vitality, SF: social functioning, RE: emotional role limitations, $\mathrm{MH}$ : mental health. *Significant Bonferroni-corrected t test comparing patients in relapse to patients in remission $(\mathrm{p}<0.00625)$. 
Table 1

Participant characteristics $(\mathrm{n}=228)$.

\begin{tabular}{|c|c|c|c|}
\hline \multirow[t]{2}{*}{ Characteristic } & $\begin{array}{c}\text { Relapse, } \\
\mathrm{n}=64\end{array}$ & $\begin{array}{c}\text { Remission, } \\
\mathrm{n}=164\end{array}$ & \\
\hline & \multicolumn{2}{|c|}{ Mean \pm SD or $\%$} & Range \\
\hline \multicolumn{4}{|l|}{ Demographic data } \\
\hline Age, yrs & $48.9 \pm 12.8$ & $51.9 \pm 13.4$ & $20.0-82.0$ \\
\hline Female, $\%$ & 75.0 & 67.7 & \\
\hline White, \% & 89.1 & 92.1 & \\
\hline \multicolumn{4}{|l|}{ Education, $\% *$} \\
\hline High school or less & 18.6 & 17.3 & $4.0-22.0 \mathrm{yrs}$ \\
\hline Some college & 46.8 & 50.0 & \\
\hline College graduate or more & 30.7 & 32.7 & \\
\hline Has a spouse/partner, $\%$ & 76.6 & 83.5 & \\
\hline Health insurance, $\%$ & 95.3 & 92.6 & \\
\hline \multicolumn{4}{|l|}{ Clinical data } \\
\hline \multicolumn{4}{|l|}{ Disease type ${ }^{*}, \%$} \\
\hline ANCA-associated vasculitis & 51.6 & 62.2 & \\
\hline Churg-Strauss syndrome & 10.9 & 13.4 & \\
\hline Microscopic polyangiitis & 3.1 & 9.8 & \\
\hline Takayasu arteritis & 7.8 & 3.7 & \\
\hline Other & 26.6 & 11.0 & \\
\hline Years with disease & $5.2 \pm 5.7$ & $6.9 \pm 6.3$ & $0.5-36.5$ \\
\hline \multicolumn{4}{|l|}{ Support } \\
\hline Physician support $^{\dagger}$ & $2.0 \pm 0.7$ & $2.1 \pm 0.7$ & $1.0-4.0$ \\
\hline Partner support ${ }^{\dagger}$ & $2.0 \pm 0.7$ & $2.2 \pm 0.8$ & $1.0-4.0$ \\
\hline
\end{tabular}




\section{Table 2}

Means, standard deviations, and t test statistics comparing health-related quality of life 27 of vasculitis patients in relapse and remission. Higher scores indicate better quality of life.

\begin{tabular}{lcccc}
\hline & $\begin{array}{c}\text { Relapse, } \\
\mathbf{n}=\mathbf{6 4}\end{array}$ & $\begin{array}{c}\text { Remission, } \\
\mathbf{n}=\mathbf{1 6 4}\end{array}$ & & \\
& \multicolumn{1}{c}{ Mean \pm SD } & t test & p \\
\hline Physical functioning (PF) & $36.38 \pm 12.2$ & $41.63 \pm 11.9$ & 2.96 & $0.0034^{*}$ \\
Physical role limitations (RP) & $34.58 \pm 10.1$ & $39.09 \pm 11.7$ & 2.72 & 0.0070 \\
Bodily pain (BP) & $40.35 \pm 11.0$ & $47.92 \pm 10.6$ & 4.77 & $<0.0001^{*}$ \\
General health (GH) & $33.57 \pm 7.0$ & $37.56 \pm 7.3$ & 3.77 & $0.0002^{*}$ \\
Vitality (VT) & $37.18 \pm 10.7$ & $42.35 \pm 11.8$ & 3.05 & $0.0026^{*}$ \\
Social functioning (SF) & $35.34 \pm 12.0$ & $43.40 \pm 12.0$ & 4.55 & $0.0001^{*}$ \\
Emotional role limitations (RE) & $38.66 \pm 14.3$ & $44.35 \pm 13.1$ & 2.81 & $0.0055^{*}$ \\
Mental health (MH) & $41.50 \pm 12.4$ & $47.53 \pm 11.1$ & 3.57 & $0.0004^{*}$ \\
\hline * & & & &
\end{tabular}




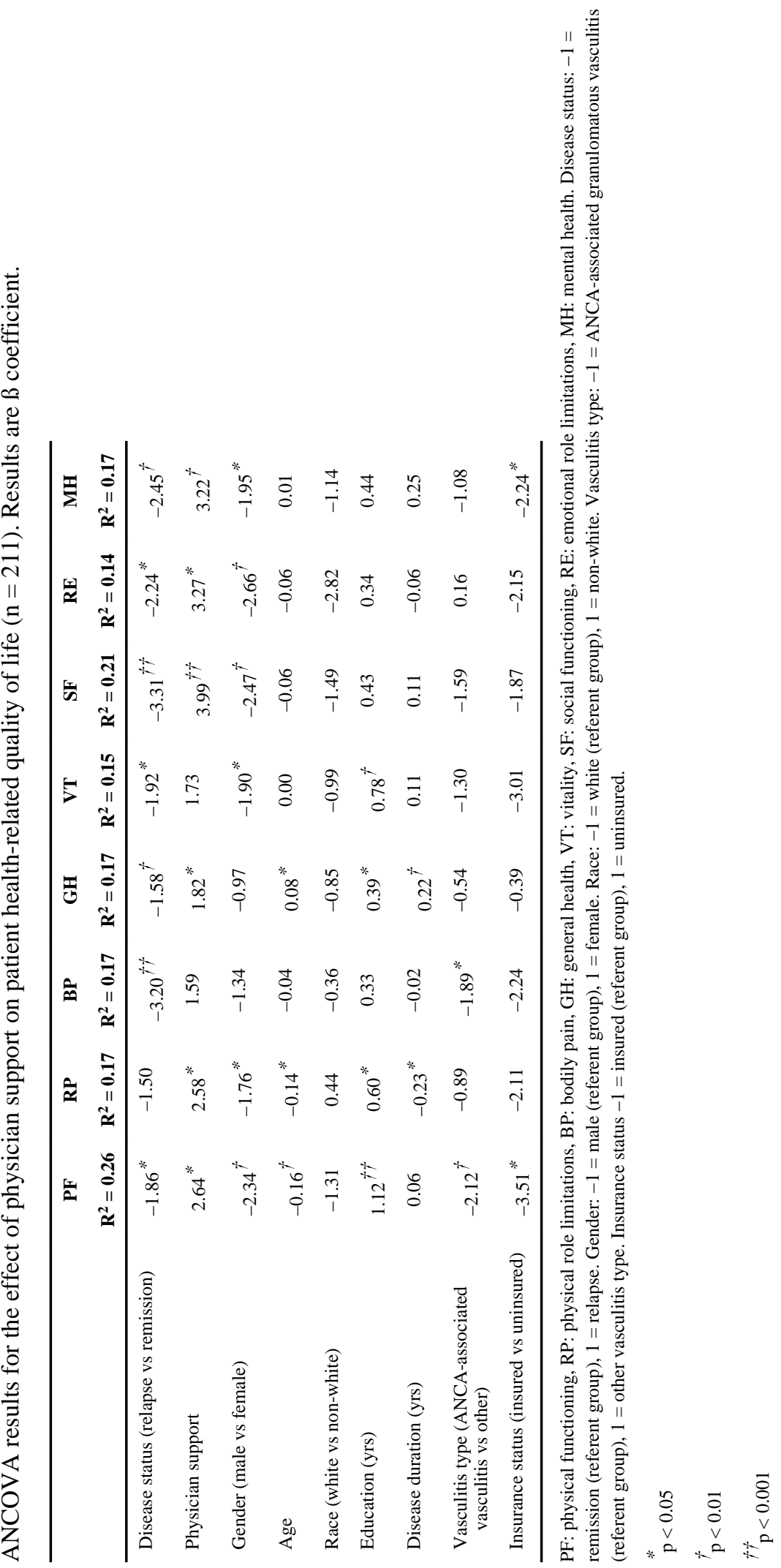

J Rheumatol. Author manuscript; available in PMC 2013 June 10. 
Table 4

Slope estimates for the effect of physician and partner support on health-related quality of life for patients experiencing a relapse and patients in remission.

\begin{tabular}{lcccc}
\hline & \multicolumn{2}{c}{$\begin{array}{c}\text { Physician Support, } \\
\mathbf{n = 2 1 1}\end{array}$} & \multicolumn{2}{c}{$\begin{array}{c}\text { Partner Support, } \\
\mathbf{n}=\mathbf{1 7 5}\end{array}$} \\
& $\begin{array}{c}\text { Relapse Slope, } \\
(\mathbf{9 5 \%} \text { CI })\end{array}$ & $\begin{array}{c}\text { Remission Slope, } \\
(\mathbf{9 5 \%} \text { CI })\end{array}$ & $\begin{array}{c}\text { Relapse Slope, } \\
(\mathbf{9 5 \%} \text { CI) }\end{array}$ & $\begin{array}{c}\text { Remission Slope, } \\
\mathbf{( 9 5 \% ~ C I ) ~}\end{array}$ \\
\hline Physical functioning & $4.23(0.39,8.07)$ & $1.95(-0.58,4.48)$ & $5.49(1.05,9.92)$ & $1.32(-1.08,3.71)$ \\
Physical role limitations & $3.56(-0.33,7.45)$ & $2.16(-0.41,4.72)$ & $4.76(0.37,9.14)$ & $2.43(0.05,4.80)$ \\
Bodily pain & $3.12(-0.61,6.85)$ & $0.92(-1.54,3.38)$ & $2.47(-1.89,6.83)$ & $1.32(-1.04,3.67)$ \\
General health & $2.62(0.10,5.14)$ & $1.46(-0.20,3.12)$ & $3.42(0.36,6.48)$ & $1.07(-0.58,2.72)$ \\
Vitality & $2.75(-1.29,6.79)$ & $1.28(-1.38,3.94)$ & $3.15(-1.57,7.86)$ & $1.19(-1.36,3.37)$ \\
Social functioning & $3.80(-0.37,7.96)$ & $4.07(1.33,6.82)$ & $3.70(-1.00,8.40)$ & $2.60(0.06,5.14)$ \\
Emotional role limitations & $4.80(0.15,9.44)$ & $2.60(-0.46,5.66)$ & $10.86(5.59,16.13)$ & $3.46(0.61,6.31)$ \\
Mental health & $4.11(0.09,8.12)$ & $2.84(0.19,5.48)$ & $4.61(0.04,9.18)$ & $2.10(-0.37,4.57)$ \\
\hline
\end{tabular}




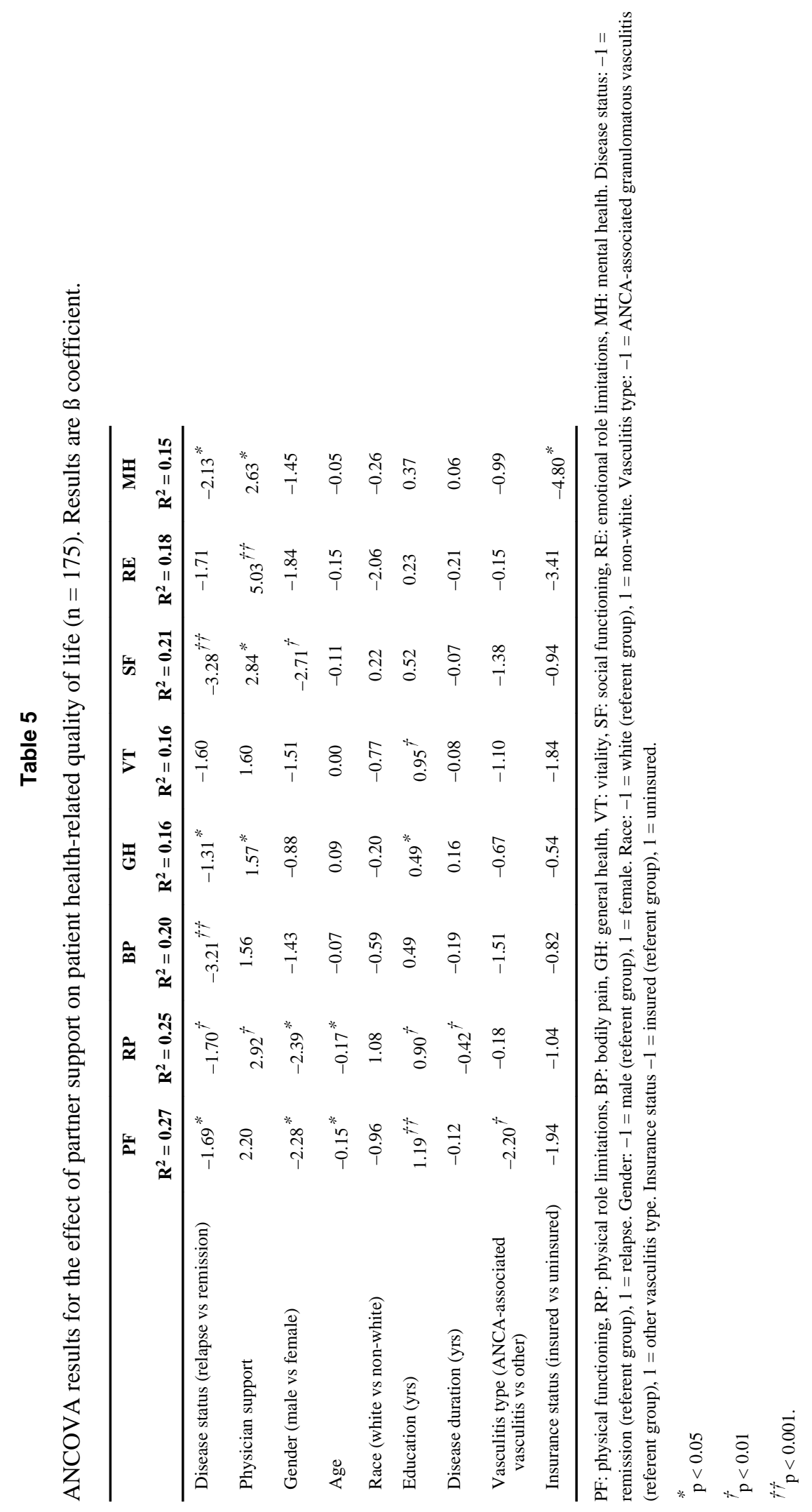

